\title{
Photogrammetric evaluation of shear modulus of glulam timber using torsion test method and dual stereo vision system
}

\author{
Ahmed Mohamed ${ }^{1,2} \cdot$ Yu Deng $^{3} \cdot$ Hexin Zhang $^{1}$ (D) Simon H. F. Wong ${ }^{4} \cdot$ Kal Uheida $^{1} \cdot$ Y. X. Zhang ${ }^{5} \cdot$ Mei-Chun Zhu $^{5}$. \\ Martin Lehmann ${ }^{6} \cdot$ Yanfang Quan $^{3}$
}

Received: 12 September 2020 / Accepted: 11 June 2021 / Published online: 5 July 2021

(c) Crown 2021

\begin{abstract}
The shear modulus of timber and timber-based composite materials is a fundamental mechanical property, which is used in the design of timber and engineered wood products. The problem of experimentally determining appropriate values of shear modulus for timber-based composite is not as simple and straightforward as in isotropic materials. Although the torsion test is a recommended standard approach to determine the shear modulus of structural-size timber and glulam beams, it is difficult to measure the rotational deformations of the timber beams. Therefore, in this paper, a stereo camera system combined with a photogrammetric approach is proposed to evaluate the values and variations of the shear modulus of glulam beams under the torsion test. The photogrammetric approach is a non-contact method, which provides an efficient and alternative approach for measuring the deformations of the torsion specimens in three dimensions. A series of experiments was conducted on glulam timber beams under the torsion test to investigate the applicability of the optical approach to evaluate the values and variations of shear modulus as well as to investigate the effect of applying torques in a clockwise or anticlockwise direction on the shear modulus of the beams. This optical system not only allows the performance and reliability of the traditional sensors to be assessed, but also allows the rotational deformation of the torsion samples to be monitored at various locations. This enables the values of shear modulus at different cross-sections of the torsion specimens to be evaluated without the need to use more devices. The test results showed that applying torques to the glulam timber specimens during loading and unloading in either a clockwise or anticlockwise direction does not influence or cause a significant change in the shear modulus of the beams. By comparing shear modulus values of glulam beams measured based on different shear spans, it was found that the larger the shear span the smaller the shear modulus value. This might indicate that the variations of shear modulus values at these different gauge lengths need to be considered.
\end{abstract}

Hexin Zhang

j.zhang@napier.ac.uk

1 School of Engineering and the Built Environment, Edinburgh Napier University, 10 Colinton Road, Edinburgh EH10 5DT, Scotland, UK

2 Civil Engineering Department, Faculty of Engineering, Omar Al-Mukhtar University, Al Bayda, Libya

3 School of Civil Engineering and Architecture, Guangxi University of Science and Technology, Liuzhou 545006, China

4 Department of Construction Technology and Engineering, Technological Higher Education Institute of Hong Kong, 20A Tsing Yi Road, Tsing Yi Island, New Territories, Hong Kong

5 Department of Civil Engineering, Shanghai Normal University, Shanghai, China

6 Institute for Materials and Wood Technology, Bern University of Applied Sciences, Solothurnstrasse 102, 2504 Biel, Switzerland

\section{Introduction}

The shear modulus of produced timber and timber-based composite beams is of considerable importance as it plays a very significant role in structural modelling, such as the lateral torsional stability of beams (EN 1995-1-1 2004), and designing serviceability of wood-beam floors (Foschi 1982). It is also an important input for developing analytical and finite element models (Chui 2002; Jiang et al. 2004). The torsion test provides a state of pure shear stress distribution in the specimen (Hindman et al. 2005a; Gharavi et al. 2018, 2017; Gharavi and Zhang 2018), allowing measurement of the pure shear properties. This method is considered to be a suitable approach for determining the shear modulus of timber and timber-based composite materials. The most recently updated British Standard, BS EN 408:2010+A1:2012 (2012) recommended the torsion test as a standard approach to 
determine the shear modulus of structural-size timber and glulam beams. Recently, the torsion test has been adopted by more and more researchers (including Gupta et al. 2002; Gupta and Siller 2005; Hindman et al. 2005a, b; Khokhar et al. 2010; Zhang et al. 2011, 2012) to evaluate the shear modulus of structural-size timber and glulam beams.

In the torsion test, the exact measurement of the relative angle of twist over a gauge length is essential to determine the shear strain and hence enable the calculation of shear modulus. The rotations measured by the torsion tester machines, such as the Tinius Olsen machine, may include small slippage between the board and the clamps of the testing machine. To overcome this difficulty, angle measurement devices, such as inclinometers, are traditionally used to measure the rotations of the torsion specimens. Although this mechanical device has proven to be accurate and flexible for measuring the rotations, it presents some significant drawbacks. Configuring the sensor tends to be timeconsuming and labour intensive and it can be damaged or destroyed during destructive testing. The size of this sensor and the nature of the surface contact it is measuring have prevented it from being used to measure more details of the shear deformations, details which might help to evaluate the variations of shear modulus $(\mathrm{G})$ of timber and glulam beams. The photogrammetric approach is proposed in this research to measure the surface rotations of the torsion samples.

Monitoring tools using photogrammetry and image processing have been used in timber to measure mechanical properties, 3D displacements, or deformations at various points of the same specimen, as proposed in various experiments (Choi et al. 1991; Dahl and Malo 2009a, Dahl and Malo 2009b; Franke et al. 2007; Garcia and Orteu 2001; Maas and Hampel 2006; Guindos and Ortiz 2013; Xavier et al. 2012). In contrast to the traditional techniques, the photogrammetric approach could provide more details of angular deformation, which are necessary for providing more details of shear deformation of torsion specimens. It provides a permanent visual and measurement record for further assessment. Optical methods that give displacements or strain fields are now widely used to evaluate material properties of timber-based composite. However, most of these methods have been extremely limited to give in-plane measurements, meaning that the results are not fully applicable to real structural systems.

This paper presents the experimental studies performed to investigate the feasibility of the developed photogrammetric system on the torsion test. Torsion tests were conducted on glulam timber beams according to the BS EN 408:2010+A1:2012 (2012) procedure of the standard torsion tests. The main purpose of this study is to provide an effective alternative method for evaluating the values and the variation of the shear modulus of glulam beams. Another objective of this study was to evaluate torsional behaviour of glulam timber beams and to investigate the effect of shear spans on the values of shear modulus. This may assist in understanding the torsional behaviour of the specimens and give a basis for further studies.

\section{Shear modulus from torsion test}

The torsion test method has been included in the most recently updated British Standard, BS EN 408:2010+A1:2012 (2012) to obtain the shear modulus of timber. As described in the standard, the relative rotational displacements and the torque must be measured at two sections, which are spaced within the free testing length. Based on the Saint-Venant torsion theory of rectangular cross-section, the value of the shear modulus for each torsion specimen $\left(\mathrm{G}_{\mathrm{Tor}}\right)$ can be calculated using the equation given in BS EN 408:2010+A1:2012 (2012):

$G_{\text {Tor }}=\frac{K_{\text {Tor }} l_{1}}{\eta h b^{3}}$

where $l_{1}$ is the gauge length and $\mathrm{K}_{\text {Tor }}$ is the torque stiffness, which can be determined using a linear regression analysis conducted on the linear elastic portion of the graph of applied torque within proportional limits and relative twist of the specimen. $h$ and $b$ are the depth and width of the specimen, respectively. $\eta$ is a shape factor, which depends on the depth to width ratio and can be determined from a Table given in BS EN 408:2010+A1:2012 (2012).

\section{Materials and methods}

The rectangular cross-section timber glulam beams used in this study as samples for the torsion tests had cross sectional dimensions of about $45 \mathrm{~mm} \times 220 \mathrm{~mm}$ and the total length of each beam was about $4 \mathrm{~m}$, as shown in Fig. 1a. These beams are graded to GL24 class strength. This grade of glulam beams was selected because it is common and regularly available in the UK. As described in BS EN 408:2010+A1:2012 (2012) standard, the glulam samples were stored in a conditioning room with a constant temperature of $20{ }^{\circ} \mathrm{C}$ and a relative humidity of $65 \%$.

Before testing and in order to employ the stereo camera systems for actual angular measurements, the glulam timber beams were prepared by applying photogrammetric targets to their surfaces. This was achieved by painting the area of interest with a white paint to serve as a background, which can assist in distinguishing the targets during image processing. Then, black circular marks (targets) were painted on the background. These targets are used to measure the rotations along the depth of the test specimen. Circular marks 

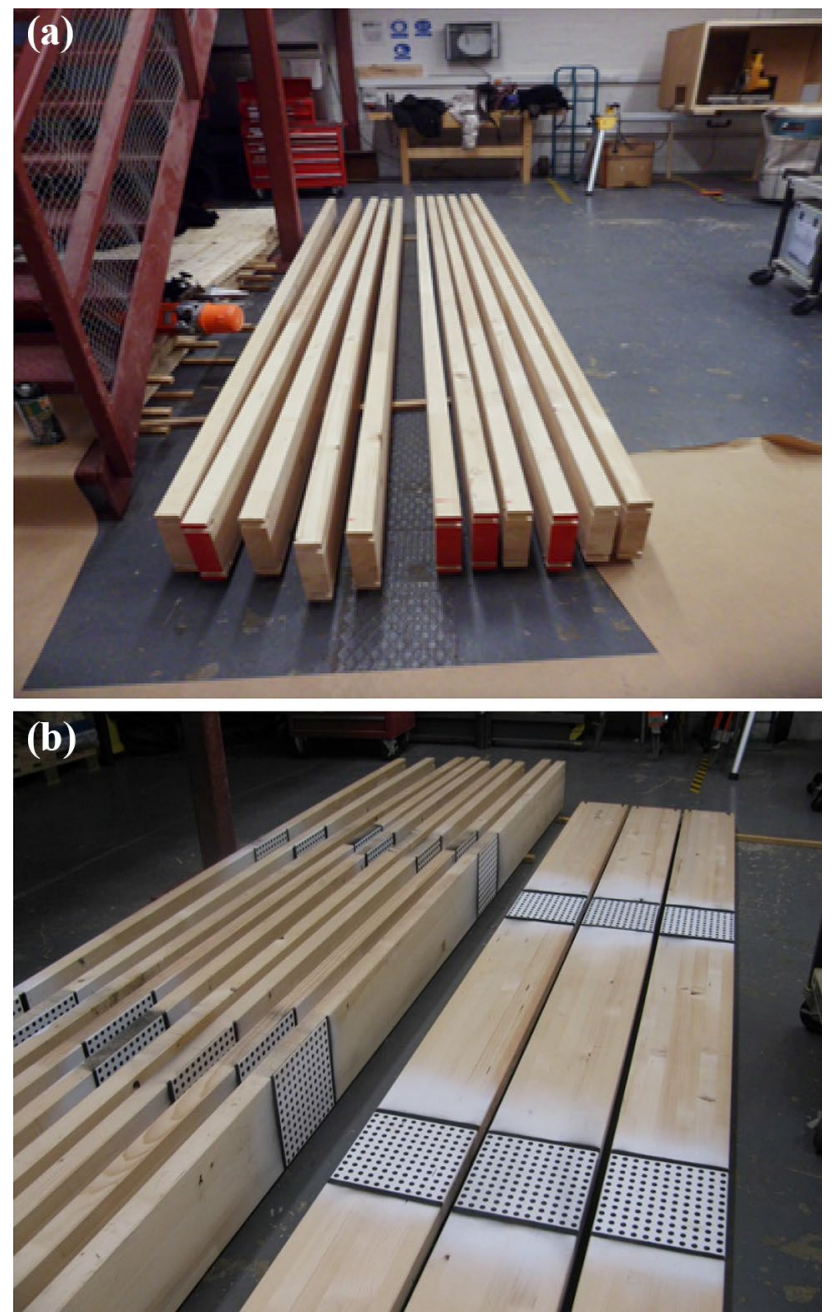

Fig. 1. Glulam beam samples before and after photogrammetric patterns painted

are preferred because their centre point can be determined with high accuracy (Steger et al. 2008). The photogrammetric patterns consist of 121 circular targets arranged in 11 columns and 11 rows. These targets were marked $20 \mathrm{~mm}$ centre to centre to give traceable marks on the sample surfaces. The radius of the circular targets is $10 \mathrm{~mm}$ and the central target was set to be an origin of the $\mathrm{X}-\mathrm{Y}$ coordinate system. Figure 1a shows an image of these glulam beams. In order to calculate the cross-sectional rotation, a straight cross-sectional reference line was linearly fitted from the 11 coordinates measured for each column. All the glulam samples after being prepared with the photogrammetric targets are shown in Fig. $1 b$.

A Tinius-Olsen (Tinius Olsen, Pennsylvania USA) torsion testing machine capable of applying up to 1 kilo newtonmetre $(\mathrm{kN}-\mathrm{m})$ torque was used to perform the torsion tests on the specimens. Inclinometers (Model IS-2-30, Level Developments, UK) were employed to measure the angles of twist of the glulam beams at the attached points. The IS-2-30 is a dual axis sensor capable of measuring angles with a measurement range of $\pm 30^{\circ}$ in two directions with an accuracy of $\pm 0.05^{\circ}$. The diameter of the circular base is $43 \mathrm{~mm}$. These inclinometers can measure the relative twist angle in both $\mathrm{X}$ and $\mathrm{Y}$ directions. A data log interface, as shown in Fig. 2, was developed by the authors of this study to simultaneously display, record and transfer data received from the inclinometers to a desktop computer, depending on the time interval specified by the user of the system.

In addition to inclinometers, two binocular stereo camera systems, as shown in Fig. 3a, were used to measure the actual rotational deformations of the long side of the cross section of the glulam specimens. Each of these sensors consists of two DMK 23GP031 cameras with a total resolution of $2592 \times 1944$ pixels and high-speed CMOS area scan sensor. These cameras were fitted with an Azure-3514M5M lens having a constant focal length of $35 \mathrm{~mm}$ and pixel size of $2.2 \mu \mathrm{m}$. Additionally, two LED light sources were employed to assist in providing a homogenous illumination of the stereo images. To capture the rotational deformations of the targets in real time, the authors of this research implemented MFC-based application, which was developed based on visual $\mathrm{C}++2010$, providing the functions necessary to calibrate the binocular system and to record the image data during testing. The graphical user interface (GUI) of the developed application, as shown in Fig. 3b, makes use of libraries included in the image processing software, HALCON (MVTech Software HALCON GmbH 2019). These include functions not only for calibrating the binocular stereo system easily and accurately but also for 3-dimensional image photogrammetry.

\section{Experimental setup and procedure}

Figure 4 shows a schematic of the components of the torsion test setup and an image of this experimental setup is shown in Fig. 5. The glulam specimen was inserted in the torsion machine and four inclinometers were attached to the upper surface of the torsion sample. For validation purposes, inclinometers $\mathrm{B}$ and $\mathrm{C}$ were placed exactly above the photogrammetric patterns. The stereo cameras, Basler Pilot piA2400-17gm camera, $5 \mathrm{M}$ pixel, Monochrome 2/3" CCD with GigE fast Ethernet interface, were mounted on a tripod and the baseline distance was set at about $25 \mathrm{~cm}$. The width and height of a cell on the CCD-chip are all $2.2 \times 10^{-3} \mathrm{~mm}$. The two stereo camera systems were placed in front of the left and right photogrammetric pattern, respectively at a distance around $2.5 \mathrm{~m}$ away from the beam. The LED light sources were focused on the region of interest to negate the influence of natural and indoor lighting and to provide a homogenous illumination of the torsion sample. Prior to all 
Fig. 2 The purpose-built dual-axis inclinometer data $\log$ system
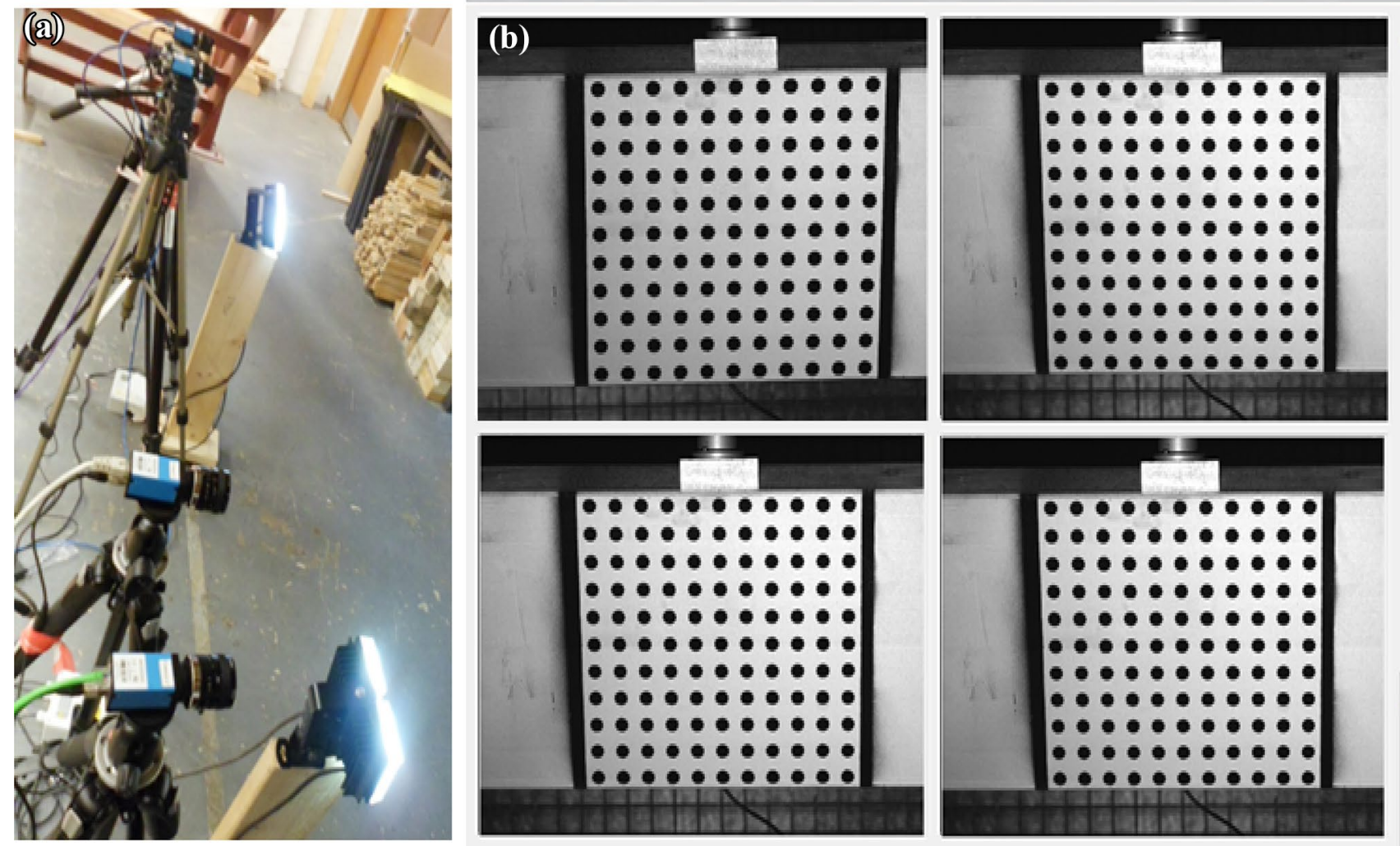

Fig. 3 a Binocular stereo camera systems, b screen shot of the target areas from four cameras. 


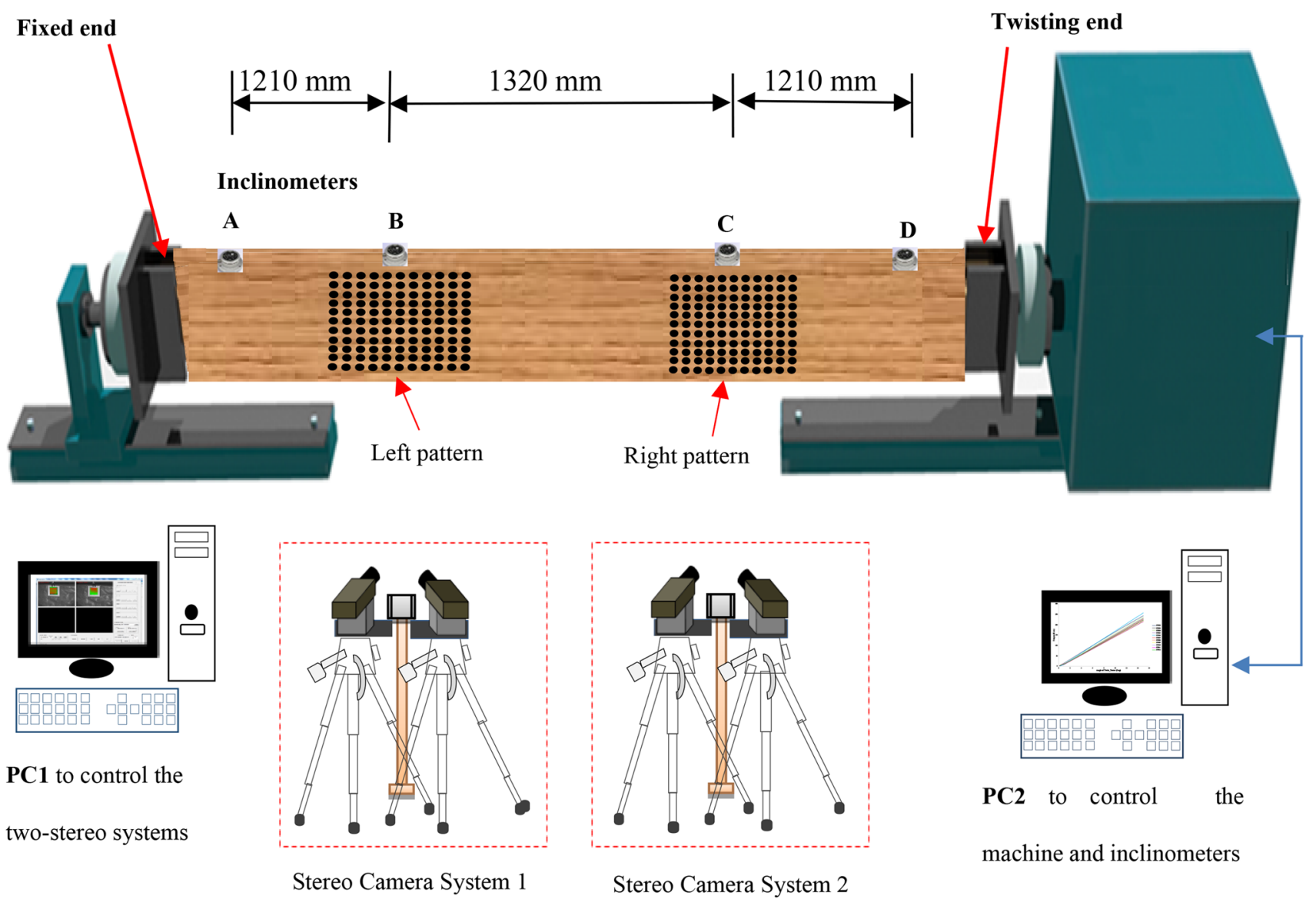

Fig. 4 Torsion test and dual stereo vision cameras setup

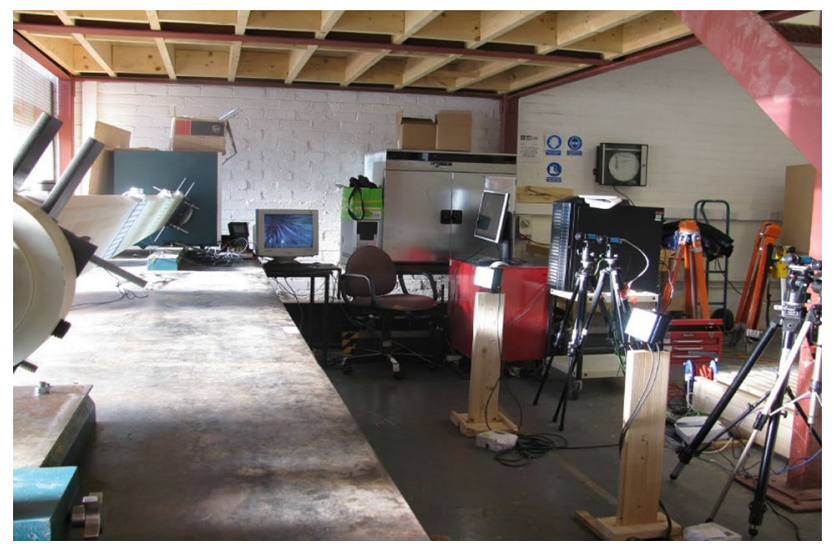

Fig. 5 Laboratory photograph of torsion test and dual stereo vision cameras setup

torsional tests, the two camera systems were calibrated using a $100 \mathrm{~mm} \times 100 \mathrm{~mm}$ calibration plate and based on the stereo camera calibration of HALCON. The standard calibration plate was chosen according to the estimated dimensions of the region of interest to be captured as described in MVTech Software HALCON GmbH (2019). This target consists of
49 marks whose 3D coordinates are known with a high accuracy. The coordinates of these targets are given in the calibration description file which contains the geometrical information of the calibration plate but different for each size of the calibration plate as mentioned in the technical reference of MVTech Software HALCON GmbH (2019). More information about the calibration of the stereo cameras is given in detail in Steger et al. (2008). Once the binocular stereo systems were calibrated, the torsion tests were carried out four times for each torsion specimen according to the BS EN 408:2010+A1:2012 (2012) procedure of the standard torsion tests.

Preliminary torsion tests were carried out on the first sample to determine the rate of loading and to estimate the elastic range of the sample in order to ensure that no permanent deformation occurred during testing under torsional loading. Each sample was tested in the same manner; by applying a torque to the specimen, in the clockwise direction within the elastic range, at a constant rate of twist equal to $5 \% \mathrm{~min}$ both in loading and unloading until the torsion angle of the tester reached $15^{\circ}$. The direction of the torsion torque was then reversed to an anticlockwise direction with the same loading rate until the torsion angle of the tester reached $15^{\circ}$. Finally, the loading 
Table 1 Internal camera parameters of the first stereo camera system

\begin{tabular}{lllll}
\hline Camera Parameter & Description & Unit & Left Camera & Right Camera \\
\hline Focus & Focal length of the lens & $\mathrm{m}$ & 0.035 & 0.035 \\
Kappa & Radial distortion coefficient & $\mathrm{m}^{-2}$ & 31.57 & -14.16 \\
Sx & Width of a cell on the CCD-chip & $\mathrm{m}$ & $2.2 \mathrm{e}-006$ & $2.2 \mathrm{e}-006$ \\
Sy & Height of a cell on the CCD-chip & $\mathrm{m}$ & $2.2 \mathrm{e}-006$ & $2.2 \mathrm{e}-006$ \\
$\mathrm{Cx}$ & X-coordinate of the image centre & Pixels & 1503.89 & 1424.04 \\
Cy & Y-coordinate of the image centre & Pixels & 957.12 & 992.70 \\
Image width & Width of the images & Pixels & 2592 & 2592 \\
Image height & Height of the images & Pixels & 1944 & 1944 \\
\hline
\end{tabular}

\section{Experimental results and discussion}

Table 2 3D pose parameters (rotation and translation)

\begin{tabular}{lll}
\hline Translation vector $(\mathrm{X} \mathrm{Y} \mathrm{Z}[\mathrm{m}])$ & $\mathrm{X}$ & 0.175 \\
& $\mathrm{Y}$ & -0.008 \\
& $\mathrm{Z}$ & 0.000 \\
Rotation angles $\left.^{\circ}{ }^{\circ}\right)$ & $\operatorname{Rot}(\mathrm{X})$ & 359.68 \\
& $\operatorname{Rot}(\mathrm{Y})$ & 355.53 \\
& $\operatorname{Rot}(\mathrm{Z})$ & 359.16 \\
\hline
\end{tabular}

chuck was then returned to its initial test position to allow the test specimen to be removed from the machine. During the torque application, the implemented software was automated to record stereo images of the two regions of interest of the sample at a time interval of $5 \mathrm{~s}$. The implemented GUI developed for the inclinometers was also employed to record their reading during the period of the test.

\subsection{Calibration results of the stereo camera systems}

In order to reconstruct the 3D coordinates of the photogrammetric targets captured by the stereo cameras, and hence determine their rotational deformations, the calibration parameters of the stereo camera systems were determined by performing the binocular stereo camera calibration of each system using the image processing software. This was achieved via a least square solution with suitable chosen parameters of the cameras that can be determined from the specification of the camera sensor and lens. Tables 1 and 2 show selected examples of the internal and external parameters, including the rotation angles and the translation vector determined from the first stereo system. A screenshot of the developed GUI during the process of calibrating the stereo camera system is shown in Fig. 6.
Fig. 6 Calibration of the stereo vision system.
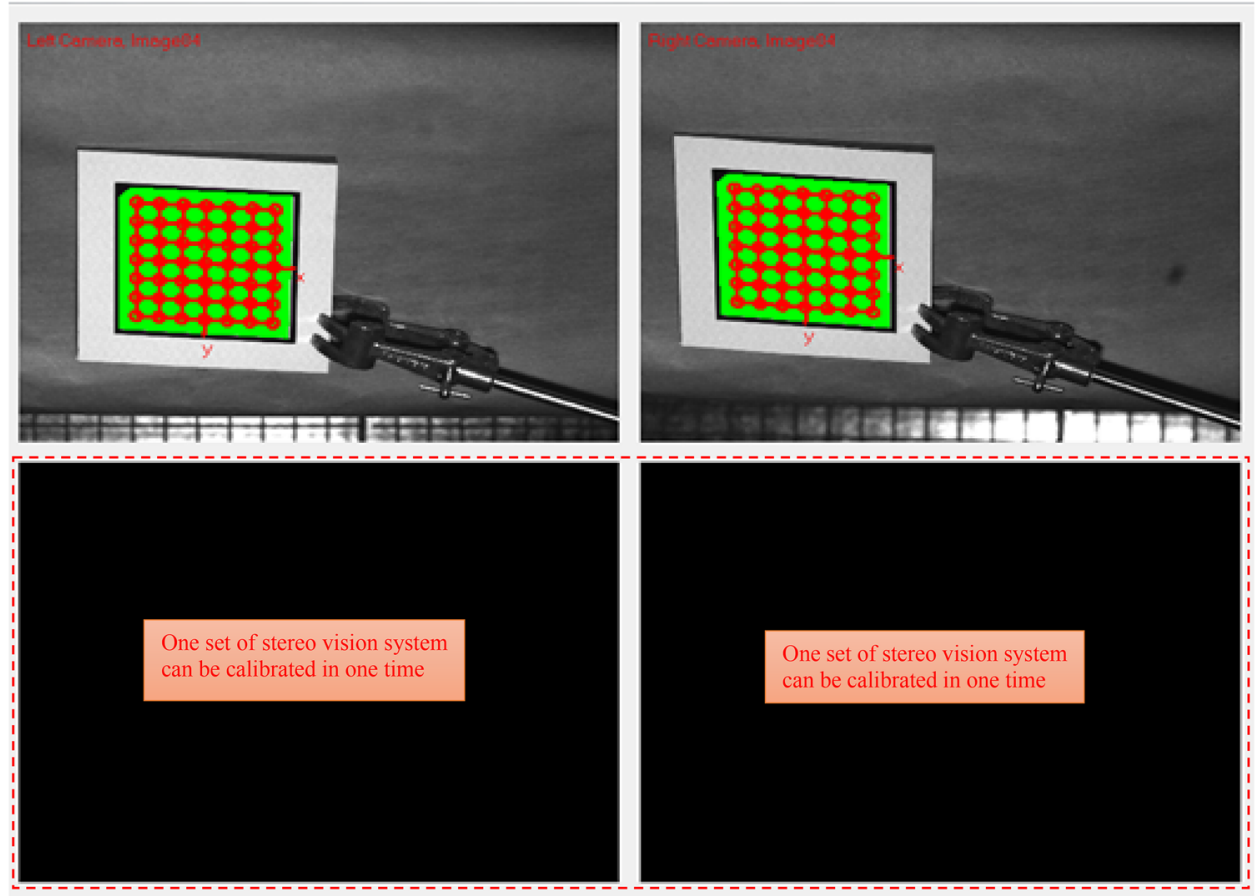


\subsection{Target tracking and 3D reconstruction}

The image processing algorithm is based on the comparison between two images acquired during the test, one before and after deformation. Figure 7 demonstrates the concept and steps involved in the algorithm. The process starts with reading the calibration files and displaying the stereo images of the targets recorded from the left and
Fig. 7 Indicative flowchart for photogrammetric measurement

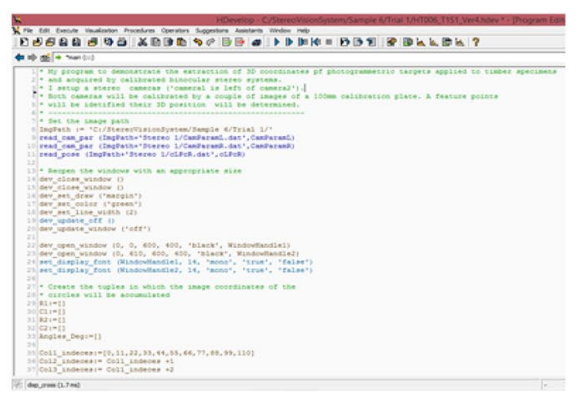

HALCON Programme

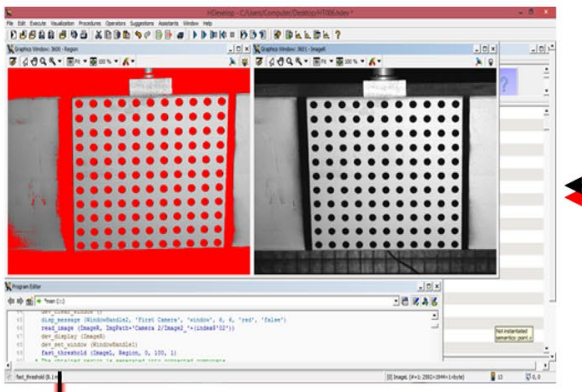

Image Segmentation

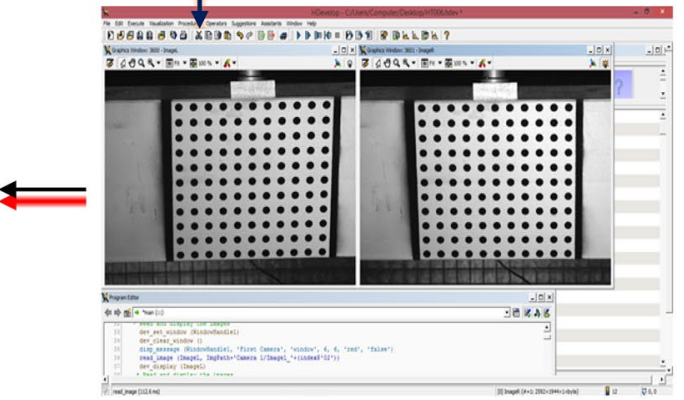

Original Image

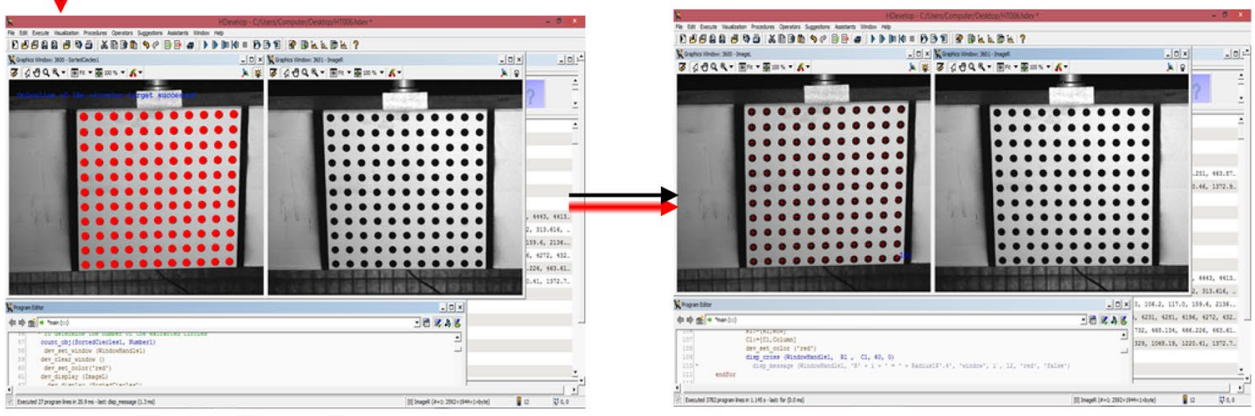

Target Detection

$$
\downarrow \text { Target Ordering }
$$

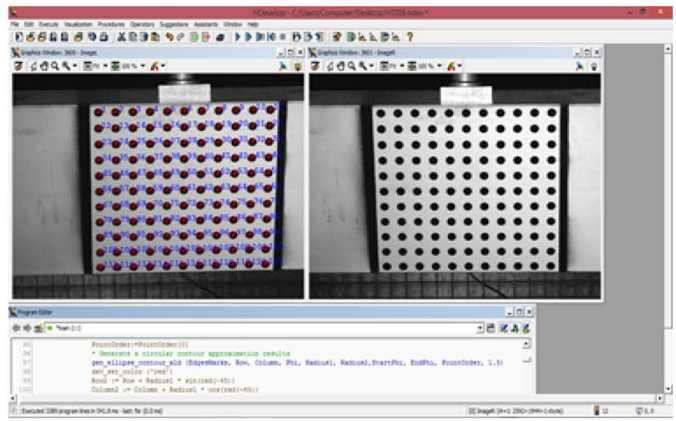

The Extracted targets 
right cameras during testing. Based on their shape and size, the potential targets were determined and tracked from the two sequences of stereo images using the sub pixel-precise segmentation method. These targets were fitted to ellipse shapes and their image coordinates in both the left and right images were measured. The 3D coordinates of the targets expressed in the camera coordinates of the left camera were determined using the theory of triangulation (Hartley and Zisserman 2003). These coordinates were then used in the calculation of the displacements and rotations of the targets during the period of tests. This was achieved by finding the pixel coordinates of the targets of each pattern and averaging these values to define a point with the average pixel coordinates of the pattern. The pixel coordinates of the other two points were determined for each pair of the stereo images by processing the initial images before applying torque to the specimens. Utilizing the calibration parameters of the stereo camera system and triangulation, the $3 \mathrm{D}$ coordinates of the three points were determined to define two vectors. Using the two vectors, the rotations of the photogrammetric patterns for each time interval were then calculated.

\subsection{Comparison of angular deformations measured by inclinometers and the photogrammetric systems}

To understand the differences between the rotations of the long and short sides of the cross section, the rotations of photogrammetric patterns 1 and 2 and the rotations of inclinometers $\mathrm{B}$ and $\mathrm{C}$ were plotted in the same figure. These data were measured in both clockwise and anticlockwise directions under torque loading and unloading phases. Figure $8 \mathrm{a}$ and $\mathrm{b}$ show some selected examples of these comparisons and indicate remarkable results. It is evident that a good agreement between the two methods has been observed and this indicates that the measurements of the rotations of the short side with inclinometers are acceptable.

To investigate the correlation between the measurements, the rotation results of the inclinometers and stereo camera systems were plotted against each other and a very strong correlation was observed for each glulam timber specimen. Selected examples of this comparison are shown in Fig. 9a and $b$ in which the rotations of specimen 4 , measured in the torsional direction by inclinometers $\mathrm{B}$ and $\mathrm{C}$ and by the first and second binocular stereo systems, were plotted against each other. These figures provide further evidence of this correlation when considering the correlation of determination $\left(\mathrm{R}^{2}\right)$ of the angular measurements of inclinometers versus stereo camera systems. From the results shown in these figures, a high degree of correlation, with an R-squared value of 0.999 , was observed.
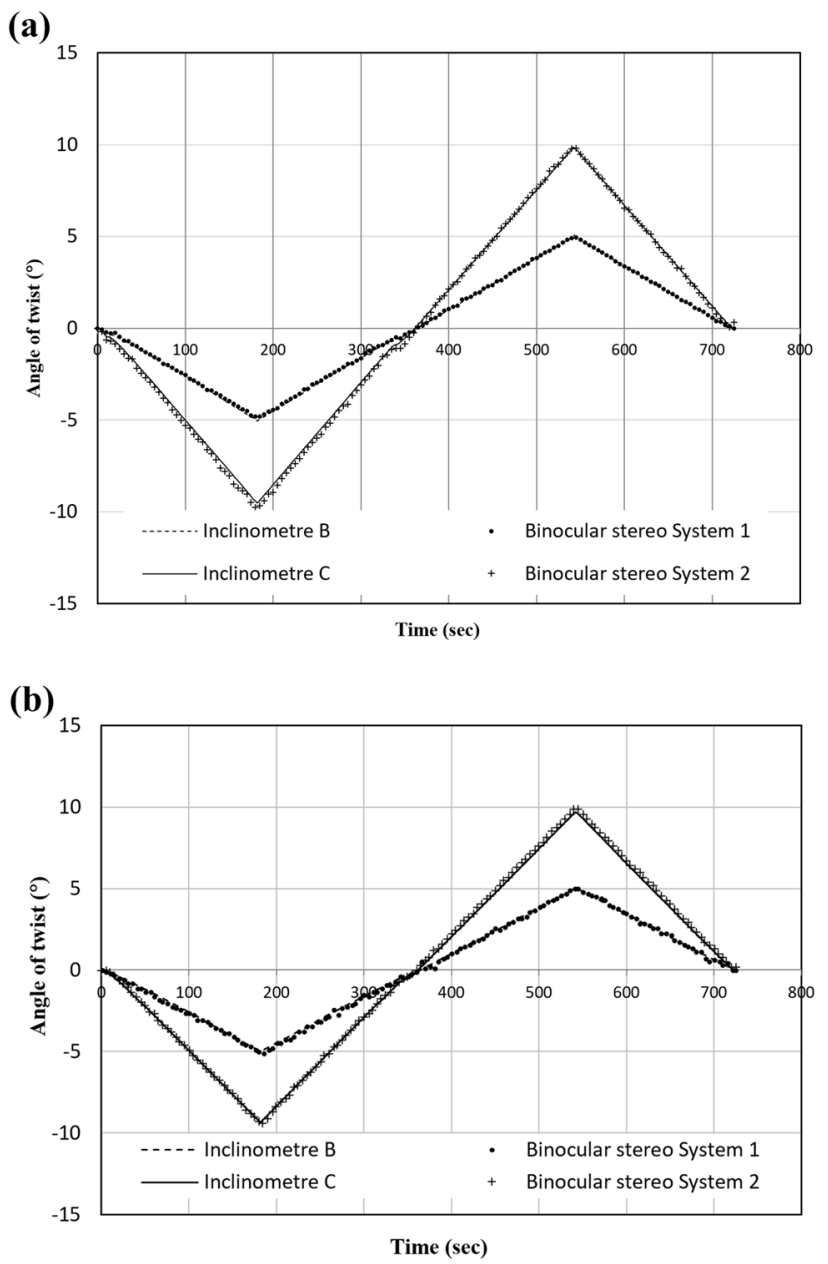

Fig. 8 Comparison between inclinometers and optical measurements for a sample 5, and b sample 9 in the first torsion test

\subsection{Torsional behaviour of the glulam timber beams}

The results of preliminary tests that were carried out on specimen 1 revealed that the maximum torque applied to the specimen was within the linear-elastic range, about $250 \mathrm{~N} \mathrm{~m}$, and the torsion specimen could be twisted by up to $15^{\circ}$ before it began to behave non-linearly. This result was found from the inclinometers, which were mounted near the reactional supports. Based on this finding, torsion tests were conducted four times on each of the remaining eleven specimens (2-12) under cyclic loading in the clockwise and anticlockwise directions. The recorded torques measured from the torque cell of the torsion machine, were analysed and displayed graphically. As an example, the torque versus time graph obtained from the first torsion test conducted on glulam specimen 2 under loading and unloading phases is shown in Fig. 10. This plot indicates that the relationship between the values of torque and the corresponding time is 

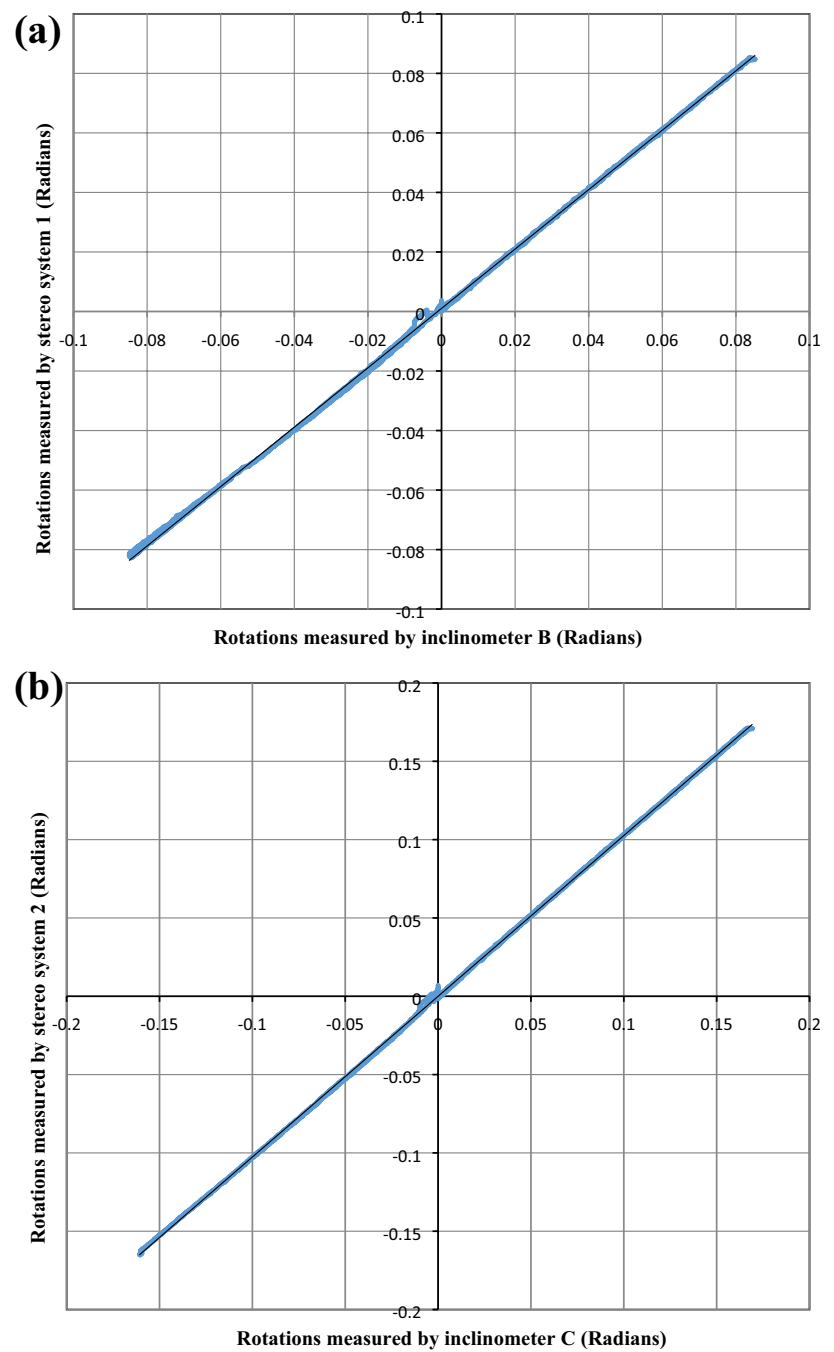

Fig. 9 Comparison of the rotations measured in specimen 4 between $\mathbf{a}$ inclinometer B and the stereo camera system 1 , and $\mathbf{b}$ inclinometer $\mathrm{C}$ and the stereo camera system

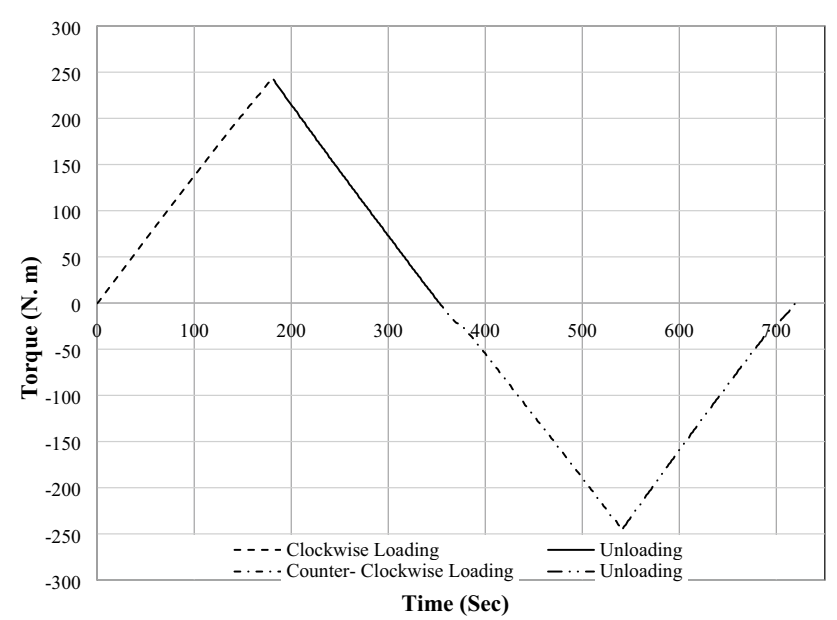

Fig. 10 Responses of sample 2 to torques during the four phases of loading in the first torsion test approximately linear during the different phases of loadings, confirming that the torsion specimen was within the elastic range. All the tested specimens deformed within the elastic range and exhibit the same linear behaviour, although there is a large degree of variability in the maximum values of torque applied to twist the torsion specimens.

\subsection{Torsional shear modulus of the beams based on the data of inclinometers}

Using Eq. (1), the shear modulus of the glulam specimens was calculated for each loading-unloading phase in both clockwise and anticlockwise directions and the average value of $\mathrm{G}$ was determined by averaging the four measured values of shear modulus from all phases. Table 3 summarizes the values of the shear modulus of the glulam specimens calculated from each loading-unloading phase in both clockwise and anticlockwise directions. The average values of the shear modulus of each timber specimen, which was determined by averaging the four measured values of shear modulus from all loading and unloading phases, are also listed in the table. As specified in Table 3, one can easily notice that for each trial of test for the same sample, the measured value of shear modulus is different. It is unclear the cause of the phenomenon. However, it does suggest that one single torsion test specified in BS EN 408:2010+A1:2012 (2012), may not be the best way of evaluating the shear modulus of the timber beams. The calculated shear modulus ranges from 593 to $757 \mathrm{MPa}$ with a mean value of $649 \mathrm{MPa}$. The difference can be explained by the fact that inhomogeneity and the variability of the wood specimens, as well as the presence of defects such as knots, affect the overall stiffness of the wood specimens. The average values of shear modulus for each torsion test are very close to each other, although there is a small difference between the values measured in the first two tests and those measured in the last two tests. These results are provided in Fig. 11, which graphically represents the average shear modulus of the test specimens calculated in each trial test. For all torsion specimens, the average values of the shear modulus calculated in the first and second trials are approximately equal, and this is true for those measured from the third and fourth trials. All these values are in good agreement and relatively close to each other with a difference range of $1-5 \%$. The shear modulus' values obtained from the first two torsion tests are relatively higher than those obtained from the last two torsion tests.

Table 4 presents the experimental average values of the shear modulus of each specimen calculated from all torsion tests for loading and unloading in both the clockwise and anticlockwise directions. The $\mathrm{G}_{\mathrm{Avg}}$ indicated in this table represents the average shear modulus of all loading cycles of a test specimen, whereas $\mathrm{G}_{\mathrm{Avg} \text {-dir }}$ represents the average shear modulus of each loading cycle of all tested specimens. 
Table 3 Shear modulus of the torsion samples in clockwise and anti-clockwise directions

\begin{tabular}{|c|c|c|c|c|c|c|c|}
\hline \multicolumn{8}{|c|}{ Average shear modulus (MPa) } \\
\hline \multirow[t]{2}{*}{ Specimen ID } & \multirow[t]{2}{*}{ Trial no } & \multicolumn{2}{|c|}{ Clockwise direction } & \multicolumn{2}{|c|}{ Anti-clockwise direction } & \multirow[t]{2}{*}{ Average } & \multirow[t]{2}{*}{ COV $\%$} \\
\hline & & Loading & Unloading & Loading & Unloading & & \\
\hline \multirow[t]{4}{*}{ HT002 } & 1 & 670 & 671 & 667 & 654 & 666 & 1.20 \\
\hline & 2 & 669 & 671 & 670 & 674 & 671 & 0.32 \\
\hline & 3 & 644 & 653 & 655 & 652 & 651 & 0.76 \\
\hline & 4 & 642 & 653 & 648 & 651 & 649 & 0.74 \\
\hline \multirow[t]{4}{*}{ HT003 } & 1 & 627 & 625 & 623 & 627 & 625 & 0.29 \\
\hline & 2 & 643 & 641 & 639 & 640 & 641 & 0.23 \\
\hline & 3 & 643 & 647 & 641 & 647 & 644 & 0.46 \\
\hline & 4 & 642 & 648 & 641 & 646 & 644 & 0.52 \\
\hline \multirow{4}{*}{ HT004 } & 1 & 700 & 699 & 680 & 681 & 690 & 1.54 \\
\hline & 2 & 697 & 702 & 687 & 684 & 692 & 1.26 \\
\hline & 3 & 675 & 673 & 670 & 670 & 672 & 0.36 \\
\hline & 4 & 672 & 673 & 675 & 670 & 673 & 0.30 \\
\hline \multirow[t]{4}{*}{ HT005 } & 1 & 672 & 673 & 662 & 669 & 669 & 0.72 \\
\hline & 2 & 669 & 673 & 662 & 668 & 668 & 0.65 \\
\hline & 3 & 644 & 650 & 647 & 644 & 646 & 0.44 \\
\hline & 4 & 641 & 649 & 647 & 645 & 645 & 0.52 \\
\hline \multirow[t]{4}{*}{ HT006 } & 1 & 753 & 755 & 751 & 744 & 751 & 0.62 \\
\hline & 2 & 750 & 756 & 757 & 744 & 752 & 0.76 \\
\hline & 3 & 729 & 737 & 735 & 731 & 733 & 0.49 \\
\hline & 4 & 726 & 737 & 728 & 732 & 731 & 0.64 \\
\hline \multirow[t]{4}{*}{ HT007 } & 1 & 627 & 626 & 627 & 623 & 626 & 0.28 \\
\hline & 2 & 623 & 625 & 627 & 622 & 624 & 0.37 \\
\hline & 3 & 606 & 610 & 605 & 604 & 606 & 0.45 \\
\hline & 4 & 605 & 610 & 606 & 605 & 607 & 0.40 \\
\hline \multirow[t]{4}{*}{ HT008 } & 1 & 671 & 674 & 666 & 669 & 670 & 0.51 \\
\hline & 2 & 670 & 672 & 664 & 668 & 669 & 0.50 \\
\hline & 3 & 668 & 671 & 657 & 654 & 663 & 1.21 \\
\hline & 4 & 666 & 671 & 658 & 657 & 663 & 1.06 \\
\hline \multirow[t]{4}{*}{ НТ009 } & 1 & 626 & 626 & 622 & 633 & 627 & 0.72 \\
\hline & 2 & 627 & 627 & 624 & 632 & 627 & 0.54 \\
\hline & 3 & 598 & 605 & 595 & 602 & 600 & 0.73 \\
\hline & 4 & 598 & 606 & 593 & 602 & 599 & 0.94 \\
\hline \multirow[t]{4}{*}{ HT010 } & 1 & 628 & 630 & 610 & 613 & 620 & 1.64 \\
\hline & 2 & 626 & 629 & 611 & 612 & 619 & 1.52 \\
\hline & 3 & 613 & 617 & 614 & 613 & 615 & 0.30 \\
\hline & 4 & 613 & 618 & 614 & 613 & 614 & 0.37 \\
\hline \multirow[t]{4}{*}{ HT011 } & 1 & 638 & 638 & 626 & 627 & 633 & 1.06 \\
\hline & 2 & 636 & 641 & 627 & 625 & 632 & 1.16 \\
\hline & 3 & 608 & 613 & 602 & 611 & 608 & 0.78 \\
\hline & 4 & 604 & 609 & 601 & 608 & 605 & 0.66 \\
\hline \multirow[t]{4}{*}{ HT012 } & 1 & 670 & 673 & 662 & 667 & 668 & 0.71 \\
\hline & 2 & 669 & 671 & 664 & 667 & 668 & 0.45 \\
\hline & 3 & 638 & 638 & 633 & 639 & 637 & 0.40 \\
\hline & 4 & 635 & 641 & 636 & 639 & 638 & 0.38 \\
\hline
\end{tabular}




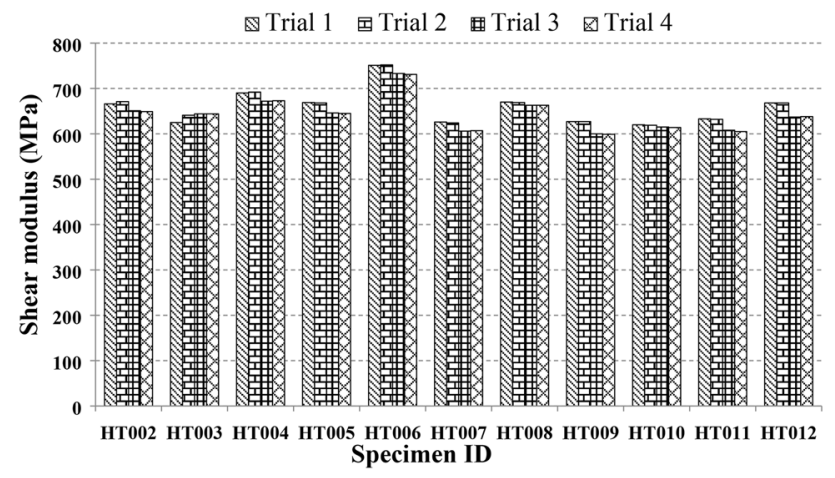

Fig. 11 Average shear modulus of the torsion specimens calculated from each torsion test

From the loading and unloading cycles, the average values of shear modulus range from 648 to $655 \mathrm{MPa}$ with a consistent standard deviation of (37-39) and a coefficient of variation (COV) of (5.7-6.1\%). The small and consistent values of $\mathrm{COV}$ may indicate that the torsion test is suitable for determining the shear modulus since the torsion specimen will be under pure torsion.

Figure 12 demonstrates a graphical representation of the average shear modulus obtained for all glulam beams. In this figure, the average $G$ results for each of the 11 glulam beams (2-12) listed in Table 4 are compared relative to the average shear modulus of all beams. The overall average $G$ of all the fabricated glulam beams tested in torsion is $651 \mathrm{MPa}$. This value agrees well with the published value of the same board of glulam beam GL24 and conforms to the requirements of EN 14080 (2013).

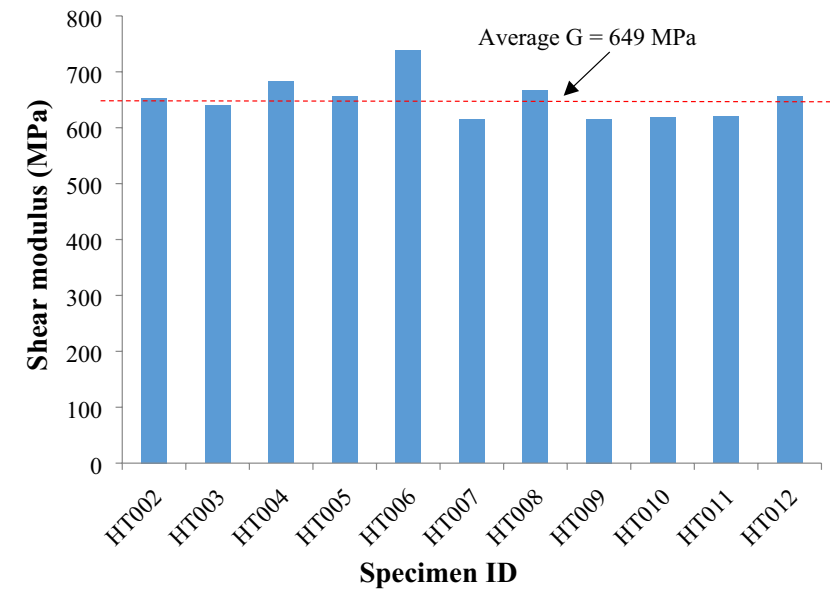

Fig. 12 Average shear modulus of the torsion specimens

\subsection{Effects of the direction of the applied torque and loading phases on the values of shear modulus}

To assess possible misalignment of the test specimens and to observe whether inducing torque in a clockwise or anticlockwise direction influences the torsional behaviour and hence the shear modulus of the specimens, the torsion tests were conducted on each torsion specimen under cyclic loading. Each torsion test consists of phases of torque loading and unloading in a clockwise direction, followed by loading and unloading phases in an anticlockwise direction. From the results of shear modulus presented in Table 5, it can be observed that the experimental values of shear modulus
Table 4 Average shear modulus of each of the torsion samples in all trial tests

\begin{tabular}{|c|c|c|c|c|c|c|c|c|}
\hline \multicolumn{9}{|c|}{ Average shear modulus (MPa) } \\
\hline \multirow[t]{2}{*}{ Specimen } & \multicolumn{3}{|c|}{ Clockwise direction } & \multicolumn{3}{|c|}{ Anticlockwise direction } & \multirow{2}{*}{$\begin{array}{l}\text { Difference } \\
\mathrm{G}_{\text {clock-Ganticlock }}\end{array}$} & \multirow[t]{2}{*}{$\mathrm{G}_{\mathrm{Avg}}$} \\
\hline & Loading & Unloading & $\mathrm{G}_{\text {Avg Clock-dir }}$ & Loading & Unloading & $\mathrm{G}_{\text {Avg Anticlock-dir }}$ & & \\
\hline HT002 & 656 & 661 & 659 & 659 & 659 & 659 & -1 & 659 \\
\hline HT003 & 639 & 640 & 640 & 636 & 640 & 638 & 2 & 639 \\
\hline HT004 & 686 & 687 & 687 & 678 & 676 & 677 & 10 & 682 \\
\hline HT005 & 656 & 661 & 659 & 655 & 656 & 655.5 & 3 & 657 \\
\hline HT006 & 740 & 746 & 743 & 743 & 738 & 740.5 & 3 & 742 \\
\hline НT007 & 615 & 618 & 617 & 616 & 614 & 615 & 2 & 616 \\
\hline HT008 & 669 & 672 & 671 & 661 & 662 & 661.5 & 9 & 666 \\
\hline НT009 & 612 & 616 & 614 & 608 & 617 & 612.5 & 2 & 613 \\
\hline HT010 & 619 & 623 & 621 & 612 & 613 & 612.5 & 9 & 617 \\
\hline HT011 & 621 & 625 & 623 & 614 & 618 & 616 & 7 & 620 \\
\hline НT012 & 653 & 656 & 655 & 649 & 653 & 651 & 4 & 653 \\
\hline $\mathrm{G}_{\text {Avg-dir }}$ & 651 & 655 & 653 & 648 & 650 & 649 & & 651 \\
\hline Std & 38 & 38 & 38 & 39 & 37 & 38 & & \\
\hline $\mathrm{COV}$ & 0.058 & 0.059 & 0.058 & 0.061 & 0.057 & 0.059 & & \\
\hline
\end{tabular}


Table 5 Shear modulus values of three spans of torsion specimens

\begin{tabular}{lllll}
\hline \multicolumn{2}{l}{ Average shear modulus (MPa) } & & \\
\hline Specimen ID & \multicolumn{2}{l}{ Shear span } & $\mathrm{G}_{\text {Avg }}$ \\
\cline { 2 - 4 } & $\mathrm{S} 1$ & $\mathrm{~S} 2$ & $\mathrm{~S} 3$ & \\
\hline HT002 & 547 & 613 & 718 & $\mathbf{6 2 6}$ \\
HT003 & 568 & 667 & 745 & $\mathbf{6 6 0}$ \\
HT004 & 562 & 667 & 745 & $\mathbf{6 5 8}$ \\
HT005 & 568 & 633 & 745 & $\mathbf{6 4 9}$ \\
HT006 & 630 & 720 & 803 & $\mathbf{7 1 8}$ \\
HT007 & 544 & 624 & 730 & $\mathbf{6 3 3}$ \\
HT008 & 571 & 667 & 799 & $\mathbf{6 7 9}$ \\
HT009 & 521 & 578 & 659 & $\mathbf{5 8 6}$ \\
HT010A & 495 & 561 & 651 & $\mathbf{5 6 9}$ \\
HT010B & 535 & 608 & 717 & $\mathbf{6 2 0}$ \\
HT011 & 541 & 624 & 740 & $\mathbf{6 3 5}$ \\
HT012 & 515 & 569 & 656 & $\mathbf{5 8 0}$ \\
G $_{\text {avg-span }}$ & $\mathbf{5 5 0}$ & $\mathbf{6 2 8}$ & $\mathbf{7 2 6}$ & $\mathbf{6 3 4}$ \\
\hline
\end{tabular}

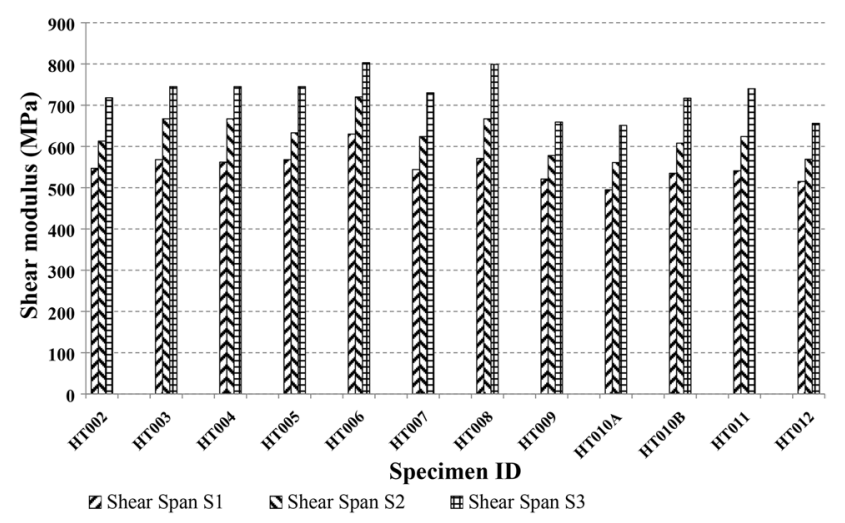

Fig. 13 Variations of shear modulus at different shear spans measured for all trial tests conducted on each torsion sample are consistent regardless of the direction of the torque or the loading phases. However, there is a small deviation, which is expected for engineered wood products such as glulam beams. As mentioned before, the experimental values of shear modulus are in good agreement and are relatively close to each other with a difference range of $1-5 \%$. This may indicate that shear modulus is less sensitive to torque direction as there was no significant influence of the torque direction on the measured shear modulus.

\subsection{Effect of shear span on the variation of shear modulus}

The torsion specimens were non-destructively evaluated under torsional loading applied within the elastic range. As a result, it becomes essential to examine the effect of span variations on the shear modulus at different cross-sections. Therefore, based on the shape of the photogrammetric patterns, shown in Fig. 13, three shear spans S1, S2, and S3 at the middle section of the torsion specimens were considered. The first shear span, S1, is the distance between Sects. 1 and 6 , representing a gauge length of $1420 \mathrm{~mm}$. The second shear span, S2, is the distance between Sects. 2 and 5 (the distance between inclinometers B and C), representing a gauge length of $1320 \mathrm{~mm}$ and the third shear span, $\mathrm{S} 3$, is the distance between Sects. 3 and 4, representing a gauge length of $1220 \mathrm{~mm}$.

In addition to the stereo images of the photogrammetric patterns, the values of torque were recorded continuously during testing. The relative rotation of each of the two crosssections over their gauge length (shear span) was measured using the 3D coordinates of the targets distributed on the longer side of the cross section. Using these data, in addition to the geometry of the torsion specimens, the shear modulus values for each shear span were calculated using Eq. (1).
Fig. 14 Diagram of the different shear spans for determining the shear modulus on various segments

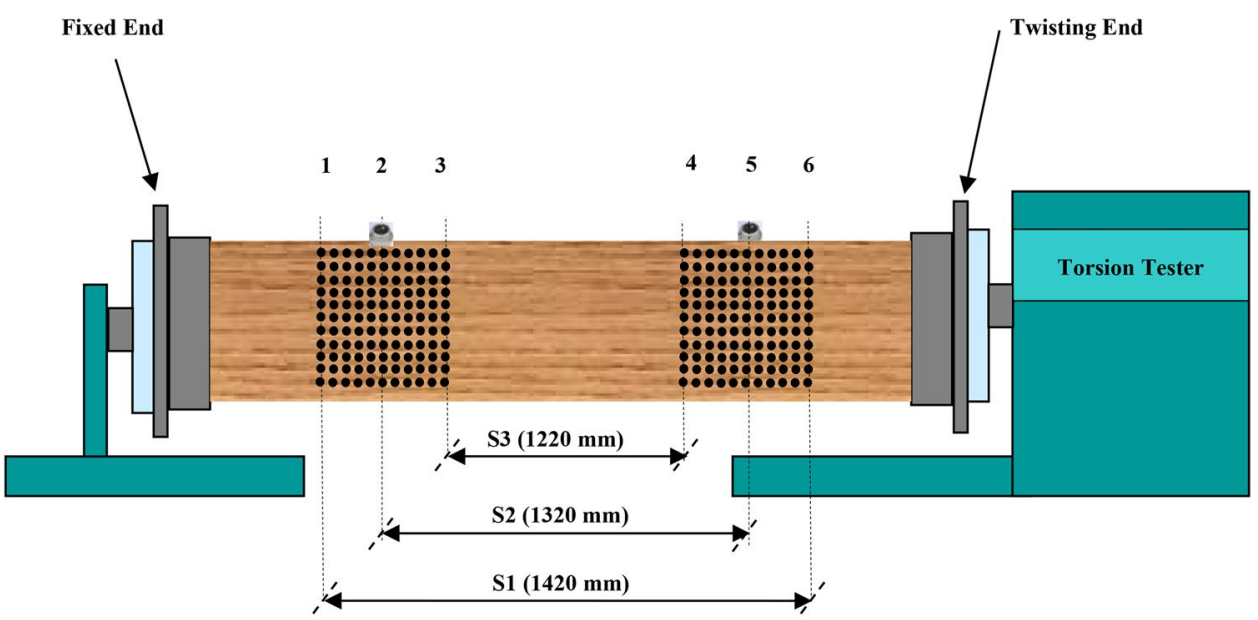


Table 6 Average shear modulus of specimen 10 calculated in different ways

\begin{tabular}{|c|c|c|c|c|c|c|c|}
\hline \multicolumn{8}{|c|}{ Average shear modulus (MPa) } \\
\hline \multirow[t]{2}{*}{ Specimen ID } & \multirow[t]{2}{*}{ Test no } & \multicolumn{2}{|c|}{ Clockwise direction } & \multicolumn{2}{|c|}{ Anti-clockwise direction } & \multirow[t]{2}{*}{ Average } & \multirow[t]{2}{*}{$\mathrm{COV} \%$} \\
\hline & & Loading & Unloading & Loading & Unloading & & \\
\hline \multirow[t]{4}{*}{ HT010A } & 1 & 628 & 630 & 610 & 613 & 620 & 1.64 \\
\hline & 2 & 626 & 629 & 611 & 612 & 619 & 1.52 \\
\hline & 3 & 613 & 617 & 614 & 613 & 615 & 0.30 \\
\hline & 4 & 613 & 618 & 614 & 613 & 614 & 0.37 \\
\hline \multirow[t]{4}{*}{ НT010B } & 1 & 608 & 612 & 609 & 618 & 612 & 0.71 \\
\hline & 2 & 607 & 613 & 608 & 619 & 612 & 0.86 \\
\hline & 3 & 629 & 634 & 624 & 629 & 629 & 0.69 \\
\hline & 4 & 628 & 633 & 623 & 629 & 628 & 0.68 \\
\hline
\end{tabular}

Four torsion tests were conducted on each torsion specimen and the results were averaged. From these results, values of $\mathrm{G}$ were obtained for the three shear spans. Table 4 presents the calculated average values of the shear modulus of the three regions of each specimen. The $\mathrm{G}_{\mathrm{Avg}}$ indicated in this table represents the average shear modulus of all shear spans of a test specimen, whereas $G_{\text {Avg-span }}$ represents the average shear modulus of each shear span of all tested specimens. From Table 4, it can be observed that the average shear modulus varies significantly when considering the three different shear spans of each timber beam.

The largest shear modulus appears to occur at the lowest shear span, which is far away from the gripping. On the other hand, the largest span, which is very close to the gripping, attained the smallest shear modulus. The same trend of variation was observed in all test specimens. This result can be clearly observed from the charts plotted in Fig. 14. The values of the shear modulus calculated in the shear span S2 are 10-16\% higher than those calculated in the larger span S1 and about $12-17 \%$ lower than those calculated in the smaller span S3. For instance, the shear modulus of $613 \mathrm{MPa}$ was attained for shear span $\mathrm{S} 2$ of specimen 2, which was $11 \%$ higher than the average shear modulus of S1 and 15\% lower than the average shear modulus of S3. The main reason for this effect could be that the larger span considered in this study is between two sections and one of them is close to the rotating end of the test specimen. The rotation angles affect the shear stiffness and hence the values of shear modulus. The angle of twist in each length is inversely proportional to the shear modulus. From these results, and within the selected shear spans, it can be concluded that the larger the shear span the smaller the value of shear modulus.

\subsection{Influence of inverting the glulam samples}

To investigate the effects of inverting the torsion samples on the torsional behaviour, sample 10 was tested under torsional loads in two ways: the right way up and upside down. Therefore, two names, 10A and 10B, were defined for this specimen to define the right way up and upside down, respectively. Table 6 reports the average shear modulus of this specimen calculated in both orientations. When installing torsion specimens, the right-side up, the average values of shear modulus calculated from the first and second trials are relatively higher than those measured from the third and fourth trials. On the other hand, when inverting specimen 10, the average values of the shear modulus calculated from the first and second trials are relatively smaller than those calculated from the third and fourth trials. It can be concluded that mounting the torsion specimens the right way up during the torsion test yields higher values of shear modulus than those obtained when inverting the specimen, although this finding was based on only a single piece of glulam beam.

\subsection{Discussion on the torsion test method and photogrammetry method}

Although the torsion test method may be a better approach to determine the shear properties of structural-size timbercomposite materials, this method has rarely been employed for the determination of G. This is due to the lack of information available for proper use of the torsion test method, in addition to the difficulty of measuring reliable angular deformations of the test specimen using the torsion testing machines, such as the Tinius Olsen Machine. Therefore, the photogrammetric approach was proposed for this type of measurement, aiming to provide further understanding of the torsional behaviour of the glulam beams. 
This research describes the proposed non-contact photogrammetric approach and investigates its ability to evaluate the shear modulus of glulam timber beams. The research focused mainly on the experimental study of torsion on structural-size glulam beams. Based on the experimental work of this research, the following conclusions can be drawn:

The proposed method provides a cost-effective and non-contact method for determining reliable deformations at multiple locations on the tested specimen, which may assist in evaluating the values and variations of the $\mathrm{G}$ of glulam timber beams. This technique overcomes the limitations of traditional contact devices, which only measure the angular deformation on a restricted number of points on the surface of the torsion specimens and can be destroyed during destructive tests.

The test results showed that applying torques to the torsion specimens during loading and unloading in either a clockwise or anticlockwise direction does not influence their stiffness and hence their shear modulus.

The average values of the shear modulus of the laminated timber specimens ranged from 593 to $757 \mathrm{MPa}$. The difference can be attributed to the inhomogeneity and the variability of the wood specimens as well as the presence of defects such as knots which affect the overall stiffness of the wood specimens. The overall average $\mathrm{G}$ of all the glulam beams tested in torsion is $649 \mathrm{MPa}$. This value agrees well with the published value of the same board of glulam beam GL24 and conforms to the requirements of EN 14080 (2013), which gives characteristic material properties for homogenous and combined glulam members.

To investigate the effects of inserting the torsion samples upside down on the torsional behaviour, sample 10 was tested under torsional loads in two ways: the right way up and upside down. It was observed that mounting the torsion specimens the right way up during the torsion test yields higher values of shear modulus than those obtained when inserting the specimens upside down, although this finding was only based on a single piece of glulam beam.

The photogrammetric approach enabled the investigation of the influence of the shear span on the shear modulus of the tested glulam beams under the torsion tests. It was apparent that the shear modulus varied significantly with the different shear spans (12-17\%). The test results of all the tested specimens revealed that the larger the shear span the smaller the value of shear modulus.

\section{Conclusion and recommendations}

This research quantifies values and variations of the shear modulus of the glulam specimens under the torsion test according to the BS EN 408:2010+A1:2012 (2012) standard method with the help of the developed photogrammetric method. Future research efforts that could be investigated based upon the results of this research include the following:

1. The torsion test method is recommended by BS EN 408:2010+A1:2012 (2012) to evaluate the shear modulus of structural-size specimens. However, this standard does not adequately address the test procedure in greater detail, especially the appropriate way to measure the rotational deformation of the torsion specimens. This investigation proved that the value and variations of the shear modulus can be obtained from the torsion tests by using the photogrammetric technique. The inclusive findings provided by the optical system on the use of the torsion test could contribute to the experimental test procedure described in the above-mentioned standard.

2. Since the shear modulus is a fundamental mechanical property of wood, it would be of great interest to apply the photogrammetric approach in the shear field test and investigate the correlation between the shear modulus and modulus of elasticity for the glulam timber beams.

3. The torsion tests were carried out on structural-size glulam timber beams. Although clear wood may not be a better approach to determine the shear properties of the timber beams, it would be of significant interest to conduct the torsion tests on clear wood specimens and investigate the correlation between shear modulus values of the clear wood and full-size specimens.

Acknowledgements The authors would like to express their special gratitude to the financial support of the Royal Academy of Engineering-Industrial Fellowship (IF\192023), Royal Academy of Engineering_Visiting Professor (VP2021\7\12), Scottish Funding Council-Innovation Voucher: Bamboo-Timber Composite Materials for Structural Use, Lawrence Ho Research Fund, National Nature Science Foundation of China (51768008), British Council and Ministry of Education, China (UK-China-BRI Countries Education Partnership Initiative 2019), China Postdoctoral Science Foundation Project (2017M613273XB), and Liuzhou Scientific Research and Technology Development Plan (2017BC40202). The authors also acknowledge the support of Innovation Team Support Plan of Guangxi University of Science and Technology. 
Open Access This article is licensed under a Creative Commons Attribution 4.0 International License, which permits use, sharing, adaptation, distribution and reproduction in any medium or format, as long as you give appropriate credit to the original author(s) and the source, provide a link to the Creative Commons licence, and indicate if changes were made. The images or other third party material in this article are included in the article's Creative Commons licence, unless indicated otherwise in a credit line to the material. If material is not included in the article's Creative Commons licence and your intended use is not permitted by statutory regulation or exceeds the permitted use, you will need to obtain permission directly from the copyright holder. To view a copy of this licence, visit http://creativecommons.org/licenses/by/4.0/.

\section{References}

Choi D, Thorpe JL, Hanna RB (1991) Image analysis to measure strain in wood and paper. Wood Sci Technol 25(4):251-262. https://doi. org/10.1007/BF00225465

Chui Y (2002) Application of ribbed-plate theory of predict vibrational serviceability of timber floor systems, In: Proc world Conf timber Eng WCTE, vol 4., Shah Alam, Malaysia, pp 87-93

Dahl K, Malo K (2009a) Planar strain measurements on wood specimens. Exp Mech 49(4):575-586. https://doi.org/10.1007/ s11340-008-9162-0

Dahl KB, Malo K (2009b) Linear shear properties of spruce softwood. Wood Sci Technol 43(5-6):499-525. https://doi.org/10.1007/ s00226-009-0246-5

EN 14080 (2013) Timber structures. Glued laminated timber and glued solid timber. Requirements. European Committee for Standardisation, Brussels

EN 1995-1-1 (2004) Eurocode 5-design of timber structures-part 1-1: general-common rules and rules for buildings. European Committee for Standardization, Brussels

EN 408:2010+A1:2012 (2012) Timber structures—structural timber and glued laminated timber-determination of some physical and mechanical properties. European Committee for Standardisation, Brussels

Foschi RO (1982) Structural analysis of wood floor systems. J Struct Div 108(7):1557-1574. https://doi.org/10.1061/JSDEAG.0005988

Franke S, Franke B, Rautenstrauch K (2007) Strain analysis of wood components by close range photogrammetry. Mater Struct 40(1):37-46. https://doi.org/10.1617/s11527-006-9152-6

Garcia D, Orteu J-J (2001) 3D deformation measurement using stereo-correlation applied to experimental mechanics. In: Proc of the 10th international symposium deformation measurements, Orange, CA, US

Gharavi N, Zhang H (2018) Study on the impact of size and position of the shear field in determining the shear modulus of glulam beam using photogrammetry approach. World Acad Sci Eng Technol Int J Struct Constr Eng 12(3):218-222. https://doi.org/10.5281/ zenodo. 1315953

Gharavi N, Zhang H, Xie Y (2017) Evaluation of the end effect impact on the torsion test for determining the shear modulus of a timber beam through a photogrammetry approach. World Acad Sci Eng Technol Int J Mech Mechatron Eng 11(3):677-680. https://doi. org/10.5281/zenodo.1129778
Gharavi N, Zhang H, Xie Y, He T (2018) End effect on determining shear modulus of timber beams in torsion test. Constr Build Mater 164:442-450. https://doi.org/10.1016/j.conbuildmat.2017.12.191

Guindos P, Ortiz J (2013) Low cost photogrammetry as a tool for stiffness analysis and finite element validation of timber with knots in bending. Biosyst Eng 114(2):86-96. https://doi.org/10.1016/j. biosystemseng.2012.11.002

Gupta R, Siller T (2005) Shear strength of structural composite lumber using torsion tests. J Test Eval 33(2):110-117. https://doi.org/10. 1520/JTE12287

Gupta R, Heck LR, Miller TH (2002) Experimental evaluation of the torsion test for determining shear strength of structural lumber. J Test Eval 30(4):283-290. https://doi.org/10.1520/JTE12318J

Hartley R, Zisserman A (2003) Multiple view geometry in computer vision. Cambridge University Press, Cambridge

Hindman D, Manbeck HB, Janowiak JJ (2005a) Torsional rigidity of rectangular wood composite materials. Wood Fiber Sci 37(2):283-291

Hindman D, Manbeck HB, Janowiak JJ (2005b) Torsional rigidity of wood composite I-joists. Wood Fiber Sci 37(2):292-303

Jiang L, Hu L, Chui YH (2004) Finite-element model for wood-based floors with lateral reinforcements. J Struct Eng 130(7):1097-1107

Khokhar A, Zhang H, Ridley-Ellis D (2010) The shear strength, and failure modes, of timber joists obtained from the torsion test method. Proceedings of the 11th World Conference of Timber Engineering, 20-24th June, Riva del Garda, Italy

Maas H-G, Hampel U (2006) Photogrammetric techniques in civil engineering material testing and structure monitoring. Photogramm Eng Remote Sens 72(1):39-45. https://doi.org/10.14358/ PERS.72.1.39

MVTech Software HALCON GmbH (2019) The software for Machine Vision Applications. http://www.mvtech.com/halcon/

Steger C, Ulrich M, Wiedemann C (2008) Machine vision algorithms and applications. Handbook of machine vision. Wiley-VCH, Weinheim

Xavier J, De Jesus AMP, Morais JJL, Pinto JMT (2012) Stereovision measurements on evaluating the modulus of elasticity of wood by compression tests parallel to the grain. Constr Build Mater 26(1):207-215. https://doi.org/10.1016/j.conbuildmat.2011.06. 012

Zhang H, Mohamed A, Xiao Z (2011) Evaluation of shear constant of a timber beam using a photogrammetric approach. Proceedings of the Thirteenth international conference on civil, structural and environmental engineering computing. Crete, Greece. https://doi. org/10.4203/ccp. 96.164

Zhang H, Mohamed A, Smith I, Xiao Z (2012) Evaluation of shear constant of timber glulam composite with photogrammetric approach. Proceedings of the fourteenth international conference on computing in civil and building engineering, Moscow, Russia

Publisher's Note Springer Nature remains neutral with regard to jurisdictional claims in published maps and institutional affiliations. 